\title{
A reabilitação urbana e dinâmica comercial na Faixa Oriental de Lisboa (2009-2019)
}

\author{
João Oliveira \\ joao.c.h.oliveira@gmail.com, Departamento de Geografia e Planeamento Regional, Faculdade \\ de Ciências Sociais e Humanas (NOVA FCSH) \\ Teresa Santos \\ teresasantos@fcsh.unl.pt, Centro Interdisciplinar de Ciências Sociais (CICS.NOVA), Faculdade \\ de Ciências Sociais e Humanas (NOVA FCSH) \\ Nuno Pires Soares. \\ nhpsoares@fcsh.unl.pt, Centro Interdisciplinar de Ciências Sociais (CICS.NOVA), Faculdade \\ de Ciências Sociais e Humanas (NOVA FCSH)
}

Para citação: OLIVEIRA, João; SANTOS, Teresa; SOARES, Nuno Pires - A reabilitação urbana e dinâmica comercial na Faixa Oriental de Lisboa (2009/2019). Estudo Prévio 16. Lisboa: CEACT/UAL - Centro de Estudos de Arquitetura, Cidade e Território da Universidade Autónoma de Lisboa, 2019. ISSN: 2182-4339 [Disponível em: www.estudoprevio.net]. DOI: https://doi.org/10.26619/2182-4339/16.3

Artigo recebido a 10 de setembro de 2019 e aceite para publicação a 29 de novembro de 2019. Creative Commons, licença CC BY-4.0: https://creativecommons.org/licenses/by/4.0/

\section{Resumo}

Novos vetores de desenvolvimento social e cultural têm vindo a potenciar formas renovadas de sentir e pensar o território: os amplos espaços de coworking, as novas galerias de arte, a difusão dos estabelecimentos de alojamento local e o comércio orientado a um consumidor cada vez mais exigente, são apenas alguns exemplos que demonstram que a zona ribeirinha das freguesias de Marvila e Beato é hoje um verdadeiro "laboratório" no qual se pretende criar um novo espaço social e cultural. O presente trabalho teve como o objetivo analisar a dinâmica de reabilitação do edificado devoluto e a evolução económica enquanto indicadores de transformação daquela área da cidade de Lisboa, no período 2009-2019. A metodologia de trabalho, ao adotar na sua estrutura um levantamento funcional, permitiu revelar alguns dados importantes. Avaliando o parque edificado que se encontrava devoluto em 2009, nota-se que passados dez anos, $45 \%$ dos edifícios sofreram obras de reabilitação. A esta transformação acresce-se o licenciamento de novas operações urbanísticas, revelando o crescente interesse imobiliário por esta zona ribeirinha, em linha com o que se verifica noutras áreas da cidade de Lisboa. Os resultados permitiram igualmente medir o decréscimo do número de estabelecimentos comerciais, verificando-se uma redução de 28\%, entre 2010 e 2019. Verificou-se igualmente que na base económica existiu um crescimento do peso das atividades terciárias e uma desvalorização do comércio a retalho. $O$ aparecimento de estúdios de artistas, galerias de arte ou do centro cultural Fábrica Braço de Prata, com salas de concertos e exposições, entre outras, indica que esta zona oriental é também um local emergente para o lazer e a cultura na cidade de Lisboa.

Palavras-Chave: Faixa Oriental de Lisboa; Revitalização urbana; Monitorização socioespacial; Uso do solo 


\section{Introdução}

Ao longo dos últimos cem anos, a cidade de Lisboa expandiu-se essencialmente para norte (limitada fisicamente a sul pelo Rio Tejo e a oeste pela serra de Monsanto) segundo uma lógica planeada. A zona oriental foi-se isolando progressivamente, não só em relação ao conjunto da cidade, como também em relação ao rio (Ochoa, 2005). Atualmente, temos uma Lisboa burguesa e urbanisticamente pensada e a sua faixa oriental que se distingue por ter acolhido ao longo do séc. XIX e XX atividades económicas menos nobres (essencialmente ligadas ao setor secundário) enquanto a ocidente a cidade evoluía, havendo uma valorização exponencial do solo urbano (com a exceção do vale de Alcântara onde ainda persistem importantes marcas do seu passado industrial).

Fruto do arrefecimento do ritmo industrial e portuário (potenciado pela deslocalização e pelo encerramento definitivo das fábricas) (Gaspar, 2000), surgiram novas ambiguidades relativamente ao que seria o futuro deste território. Sem um plano imediato de reação a esta transformação económica, na Faixa Oriental de Lisboa assistiu-se a uma desvalorização progressiva destes territórios, sobrando lotes industriais corroídos pelo tempo. Outra consequência desse mesmo arrefecimento industrial terá sido a acentuação de desigualdades sociais, onde o desemprego e a falta de interesse político por um território marginal acabaram por ditar a criação de uma representação social relativamente negativa. A regeneração urbana, que se verificou com a Expo ' 98 , também não contagiou este território, e os poucos projetos de investimento pensados foram sendo consecutivamente adiados (Alves, 2018).

Atualmente vive-se um contexto de recuperação económica (desde 2015), com valorização de bairros anteriormente pouco procurados pelo mercado imobiliário. $O$ aumento do fluxo de turistas (que beneficiou da crise de outros destinos turísticos da bacia do mediterrâneo), a disponibilidade de voos low cost, boa promoção do turismo nacional no exterior, um maior número de estudantes Erasmus ou a criação de estatuto de residente não habitual, foram fatores que potenciaram o dinamismo no mercado habitacional e comercial atualmente sentido na cidade de Lisboa (Santos et al., 2018). A estes fatores junta-se a aposta política, por parte da Município, na reabilitação urbana, espelhada quer na revisão do Plano Diretor Municipal aprovada em 2012, quer na Estratégia de Reabilitação Urbana para Lisboa (2011-2024). De acordo com dados do INE, no $4^{\circ}$ trimestre de 2018 , Lisboa registou o preço mediano de vendas de habitação mais elevado do país $\left(3010 € / \mathrm{m}^{2}\right)$. Ao nível das freguesias, a de Marvila apresentou um preço mediano inferior ao da cidade $\left(2666 € / \mathrm{m}^{2}\right)$ mas foi a freguesia com a maior taxa de variação homóloga $(+79,8 \%)$ (INE, 2018). A freguesia de Beato, embora com menores valores medianos de vendas por $\mathrm{m}^{2}$ (aproximadamente 2300 $€ / \mathrm{m}^{2}$ ), foi a segunda freguesia com maior taxa de variação homóloga na cidade de Lisboa (aproximadamente $+48 \%$ ).

Os dados públicos que permitem avaliar estas dinâmicas encontram-se bastante desatualizados - a listagem do parque devoluto data de 2009 e o recenseamento comercial data de 2010. Torna-se deste modo necessária proceder à sua atualização para melhor compreender as mudanças mais recentes.

Através da realização de um levantamento urbanístico e funcional, realizado em março 
de 2019, pretendeu-se quantificar as mudanças ocorridas na última década na frente ribeirinha das freguesias do Beato e Marvila. O levantamento permitiu 1) atualizar os dados existentes sobre o edificado devoluto (2009) e sobre as atividades comerciais (2010) e, 2) quantificar o impacto da reabilitação no parque habitacional devoluto e caracterizar a dinâmica comercial. A área analisada ocupa $2,34 \mathrm{~km}^{2}$ e enquadra-se entre a Av. Infante D. Henrique (a sudeste), a Av. Marechal Gomes da Costa (a nordeste), a linha da Azambuja (a noroeste) e a Rua Bispo de Cochim (a sudoeste). Esta área inclui os principais eixos comerciais das duas freguesias, como as Ruas de Xabregas, do Grilo, do Beato ou de Marvila.

As próximas secções descrevem os dados e métodos selecionados e discutem os principais resultados.

\section{Dados e método}

O trabalho iniciou-se com a recolha de informação existente sobre o edificado devoluto e as atividades comerciais. Deste modo, foram utlizados os dados georreferenciados e disponibilizados na plataforma Lisboa Aberta da Câmara Municipal de Lisboa para o âmbito da estrutura económica (recenseamento comercial georreferenciado de todos os estabelecimentos comerciais de acordo com a CAE-Rev3, com última atualização em 2010). Outros dados referentes ao licenciamento de obras (2018), estabelecimentos de alojamento local (2019) e classificação do património arquitetónico foram também utilizados, recorrendo-se mais uma vez à plataforma Lisboa Aberta e posteriormente à plataforma da Direção-Geral do Património Cultural. A informação referente ao parque devoluto foi obtida numa listagem disponibilizada pela Câmara Municipal de Lisboa em 2009 e georreferenciada por Santos et al., 2015.

Após estabelecer a base geográfica dos edifícios devolutos e das atividades comerciais ao nível do piso térreo com base na informação recolhida, seguiuse o levantamento urbanístico e funcional ao longo dos dias 4, 5 e 6 de março de 2019, de modo a identificar as principais alterações. Do ponto de vista técnico, a base de trabalho para o levantamento foi estruturada de modo a ser possível recolher simultaneamente a informação relativa aos edifícios devolutos e aos estabelecimentos comerciais. Deste modo, criaram-se dois ficheiros vetoriais (do tipo poligonal para os devolutos e pontual para o comércio) em ambiente SIG para acolherem os novos atributos. Relativamente ao parque devoluto procedeu-se à recolha do seu estado de conservação atual, o seu número de pisos (acima e abaixo da cota de soleira), a sua época de construção, se estão ou não disponíveis no mercado imobiliário e a sua entidade reabilitadora/origem dos fundos caso o edifício estivesse em obras. Para o comércio recolheu-se o estado atual dos estabelecimentos (devoluto ou novo) e qual a atividade que desenvolvem de acordo com a CAE-Rev3, permitindo uma análise comparativa coerente com os dados de 2010.

A última etapa metodológica implicou a interpretação e representação da 
informação geográfica recolhida: os resultados obtidos foram tratados através de software SIG e de análise de dados e apresentados sobre a forma de cartografia temática.

\section{Resultados e discussão}

\section{Parque Devoluto}

Os novos rumos do setor imobiliário, em parte, têm-se valido de uma dinâmica de reabilitação peculiar, que tem vindo a ocorrer transversalmente em toda a cidade de Lisboa. Segundo Santos et al. (2018), o impulso reabilitador do património devoluto, promovido quer pela hasta pública, quer por particulares, surgiu após o período de estagnação económica iniciado no fim da década passada e terminado com a cessação dos resgates financeiros. Desta realidade surge um conjunto de edifícios já orientados a dois tipos de investidores alvo: por um lado, Lisboa tem vindo progressivamente a albergar um número cada vez maior de indivíduos estrangeiros que, por várias motivações, procuram investir na capital; por outro lado, é através do património reabilitado que o alojamento local se procura estabelecer, ocupando parcial ou totalmente edifícios que anteriormente estavam devolutos ou em más condições de habitabilidade.

O resultado do levantamento urbanístico efetuado ao património devoluto referenciado em 2009 pela Câmara Municipal de Lisboa está descrito na Tabela 1.

\begin{tabular}{l|lllll}
\multicolumn{3}{c}{ BEATO } & MARVILA \\
\hline 2009 & Devolutos & 49 & & 37 & \\
& Devolutos & 24 & $49 \%$ & 19 & $51 \%$ \\
& Reabilitados & 23 & $47 \%$ & 16 & $43 \%$ \\
& Em obras & 1 & $2 \%$ & 1 & $3 \%$ \\
& Demolidos & 1 & $2 \%$ & 1 & $3 \%$ \\
\hline
\end{tabular}

Tabela 1 - Atualização do estado do edificado devoluto; fonte: LU, 2019; CML, 2009

O mesmo levantamento permite, juntamente com a informação quantitativa presente na tabela, visualizar os locais onde a mudança ocorreu (figura 1). As zonas mais dinâmicas localizam-se na Rua de Xabregas e na Rua do Grilo.

Numa análise global dos dados, verifica-se que em 2009, 5\% (86 edifícios) do total do edificado da área de estudo encontrava-se devoluto. Hoje deparamo-nos com uma variação significativa, uma vez que essa percentagem se estabelece agora nos $2 \%$ (43 edifícios), resultado da reabilitação de mais de metade dos edifícios anteriormente devolutos. Prevê-se que estes valores possam ser ainda mais expressivos ao longo dos próximos anos através da aprovação da Lei de Bases da Habitação, na medida em que se pretende reconverter devolutos residenciais (cuja propriedade é do estado) em habitação a preço acessível. 


\section{estudoprévio}

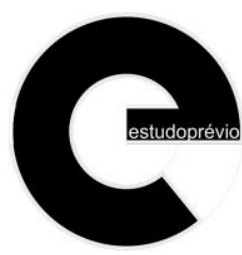

PT | P01 | EP16| w2019

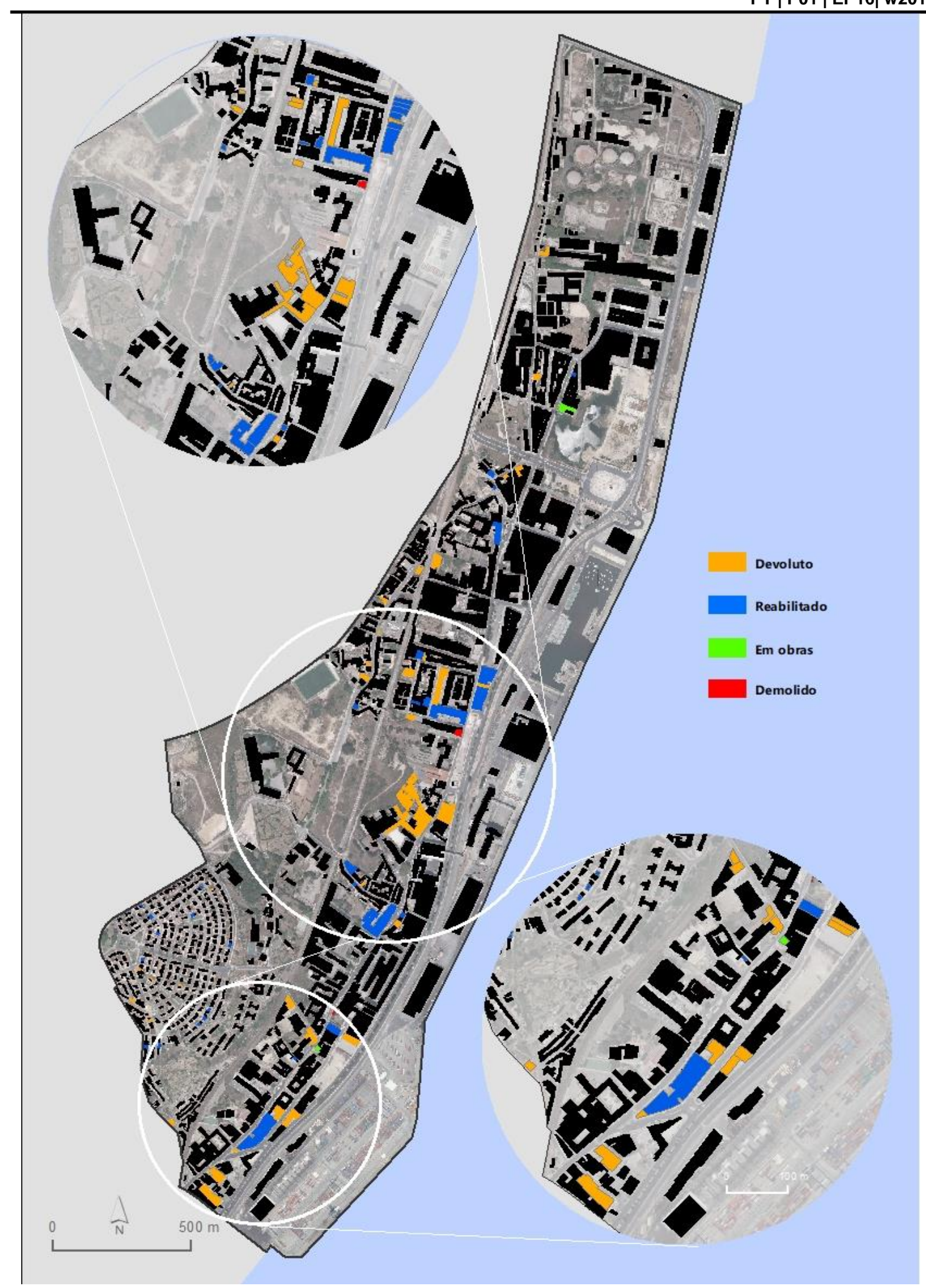

Figura 1 - Atualização do estado do edificado devoluto. Fonte: LU, 2019; CML, 2009. 


\section{Operações Urbanísticas}

De modo a corroborar a dinâmica reabilitadora do edificado devoluto, procurou-se entender de que modo esta tendência se estendia ao resto do património construído (mesmo encontrando-se com condições de habitabilidade), observando mais detalhadamente qual o tipo de operações urbanísticas que têm sido licenciadas em alvará pela autarquia. Constata-se que entre abril de 2005 e fevereiro de 2018, na porção da área de estudo referente à freguesia do Beato foram emitidos 82 alvarás para obras, enquanto que na freguesia de Marvila este valor é de 41 emissões (Tabela 2).

\begin{tabular}{l|c|c} 
& BEATO & MARVILA \\
\hline Alteração & 25 & 10 \\
Alteração durante a obra & 13 & 2 \\
Ampliação & 28 & 21 \\
Construção & 9 & 5 \\
Demolição & 6 & 2 \\
Demolição autónoma & 1 & 1
\end{tabular}

Tabela 2 - Operações urbanísticas licenciadas entre abril de 2005 e fevereiro de 2018. Fonte: CML, 2019.

A figura 2 apresenta a distribuição espacial destas operações urbanísticas de acordo com o tipo de alvará. As operações de alteração dizem respeito à "modificação das características físicas de uma edificação existente ou sua fração, designadamente a respetiva estrutura resistente, o número de fogos ou divisões interiores, ou a natureza e cor dos materiais de revestimento exterior, sem aumento da área de pavimento ou de implantação ou da cércea." (Regime Jurídico da Urbanização e Edificação - RJUE, Decreto-Lei n. $.555 / 99$ de 16 de dezembro alterado pelo Decreto-Lei n. $177 / 2001$, de 4 de julho). Estas operações encontram-se associadas maioritariamente a edifícios industriais de grande volumetria (e.g., quarteirão perto da Rua do Açúcar). As operações de "alteração durante a execução da obra" implicam mudanças no projeto de arquitetura que foram consentidas pelo respetivo departamento autárquico ao abrigo do Artigo 83. do RJUE. Este tipo de operações está presente em novos edifícios habitacionais (e.g., Rua de Marvila). As obras de ampliação compreendem alterações que "resultem no aumento da área de pavimento ou de implantação, da cércea ou do volume de uma edificação existente", e estão presentes maioritariamente em edifícios industriais (e.g., Rua do Açúcar). As obras de construção implicam novos edifícios e são visíveis a norte da área de estudo, no quarteirão que se encaixa entre a Avenida Infante D. Henrique, a Rua de Cintura do Porto e a Rua Fernando Palha. Naquela zona está previsto o empreendimento Prata Living Concept, que prevê a construção de 12 edifícios e novos espaços verdes junto ao rio, estando atualmente apenas um edifício destinado à habitação concluído. Na mesma área encontram-se dois edifícios que sofreram obras de demolição, e junto à Praça 25 de Abril um edifício que sofreu obras de demolição autónoma, não existindo perspetiva futura de edificação.

Olhando para a área de estudo, $7 \%$ da totalidade do edificado, no período de 2005 - 
2018, foi intervencionado ou pelo menos existiu a emissão de um alvará que licenciava essa intervenção. $24 \%$ das emissões de alvarás foram relativas a obras de alteração, $12 \%$ foram alterações durante a execução da obra, $40 \%$ foram obras de ampliação, $11 \%$ foram obras de construção, $7 \%$ foram empreitadas de demolição e $2 \%$ foram empreitadas de demolição autónoma. É também de realçar que de um total de 85 edifícios intervencionados com obras de alteração ou ampliação, o levantamento urbanístico realizado permitiu aferir que 21 são hoje ocupados (total ou parcialmente) com estabelecimentos turísticos de Alojamento Local. Estes valores indiciam uma intenção de melhoria das condições dos edifícios existentes e o interesse turístico desta área. A avaliação da expressão destas operações requer, porém, uma futura análise comparativa com o valor registado na cidade de Lisboa.

Ao consultar informação georreferenciada, providenciada pelo Departamento de Monitorização do Espaço Público da Câmara Municipal de Lisboa, constata-se que entre 2012 e 2017 houve apenas uma obra de pavimentação de algumas ruas do Bairro Madredeus. No âmbito do projeto Uma Praça em cada Bairro, integrado num dos eixos para o Governo da Cidade 2013/2017, existia uma intervenção planeada para a Alameda do Beato que consistia na "conversão do uso do piso térreo dos edifícios, na pedonalização da via e na definição de cérceas, materiais e paletas de cores". 


\section{estudoprévio}

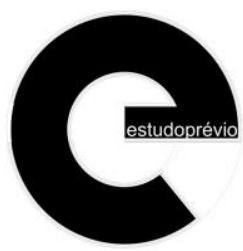

PT | P01 | EP16| w2019

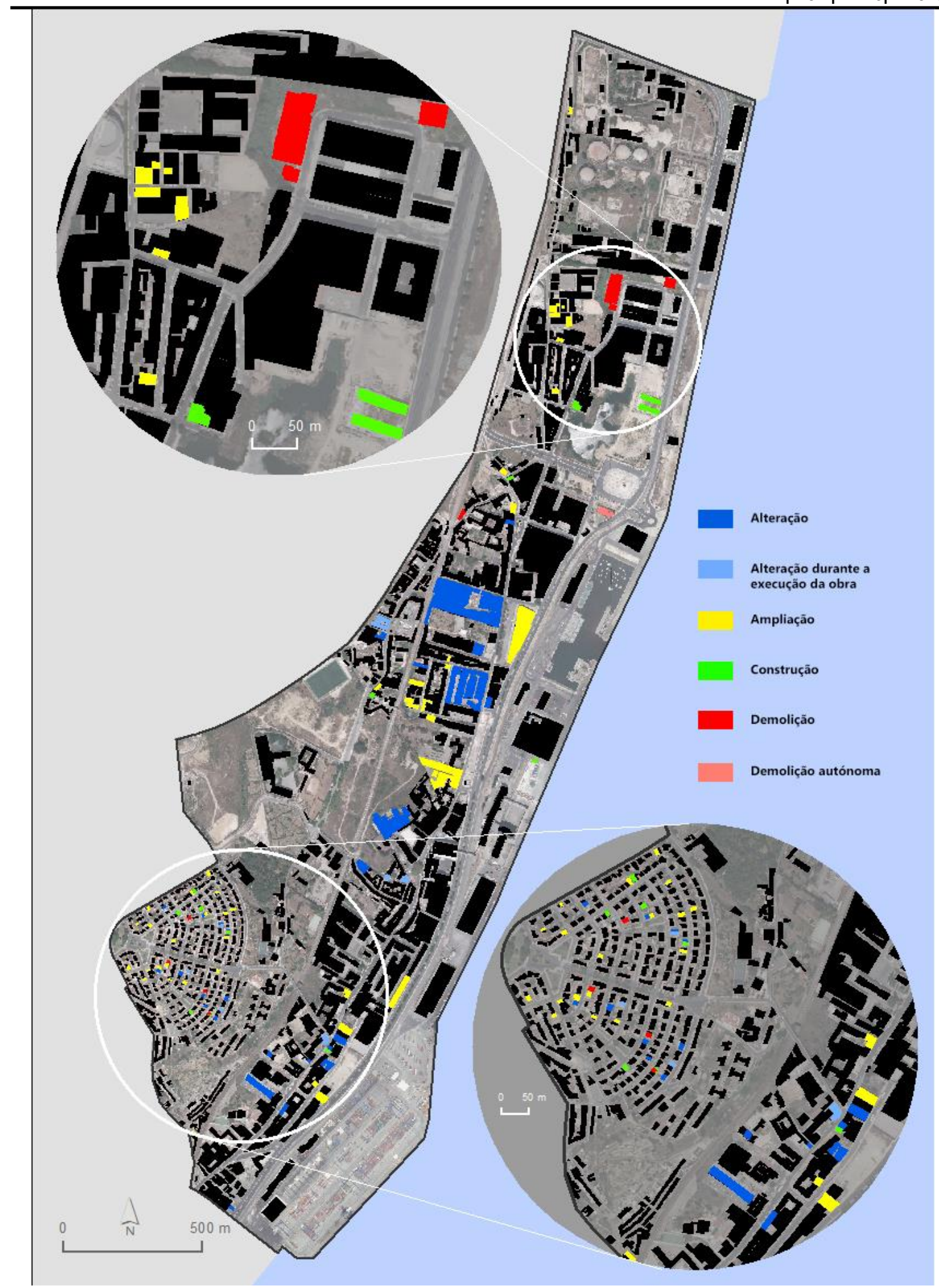

Figura 2 - Operações urbanísticas licenciadas em alvará. Fonte: Geodados, 2019. 


\section{Comércio e restante atividade económica}

Os resultados obtidos através do levantamento urbanístico realizado em março de 2019, permitem avaliar as alterações relativamente à quantidade e diversidade de atividades económicas que se estabelecem na área de estudo.

Desde 1991, data em que a Câmara Municipal de Lisboa procedeu ao primeiro censo ao comércio, que se tem observado uma flutuação do número de estabelecimentos comerciais. No referido ano estavam de portas abertas 95 estabelecimentos, desde a Rua Bispo de Cochim até ao topo da antiga fábrica de gás da Galp. Comparativamente a 2000, esse número mais que duplicou, passando para 220 estabelecimentos, com reforço do comércio a retalho e da restauração através das suas várias formas. Este aumento surtiu um efeito de intensificação comercial homogéneo em todo o território em análise, com especial destaque para a Rua Zófimo Pedroso, metade sul da Rua do Grilo e Rua de Xabregas (junto à galeria comercial). Entre 2000 e 2010 houve tendência para a manutenção das atividades, sendo que o número de estabelecimentos comerciais apenas decresceu de 220 para 216, tendo desaparecido 4 estabelecimentos dedicados ao comércio a retalho.

As transformações da estrutura económica voltaram a ser mais expressivas entre 2010 e 2019. Ao longo da área de estudo houve um decréscimo de $28 \%$ do número de estabelecimentos comerciais. Atualmente, existem 155 estabelecimentos comerciais na área de estudo, 80 dos quais mantém a atividade indicada em 2010, 13 alteraram a atividade e surgiram 62 novos estabelecimentos.

Verificou-se perda de comércio a retalho (26 estabelecimentos), com predominância dos estabelecimentos dedicados à reparação automóvel (12), mercearias (9), padarias (4) e artigos de vestuário (4). Os encerramentos são mais expressivos nas ruas que ladeiam o caminho-de-ferro na freguesia de Marvila (Rua Direita de Marvila e contíguas). Na Rua Capitão Leitão e na perpendicular Rua Afonso Annes Penedo também se assistiu ao fecho de 3 estabelecimentos que desenvolviam atividade retalhista do tipo reparação de automóveis. Ao nível da restauração, encerraram 36 estabelecimentos, maioritariamente restaurantes (17), seguidos de cafés e/ou pastelarias (9), snack-bares (6), e outros estabelecimentos (4).

Entre os novos estabelecimentos e aqueles que mantiveram ou alteram a sua atividade, são identificáveis 4 tipologias onde o comércio se desenvolve com mais intensidade (figura 4). Iniciando a análise de norte para sul, a primeira tipologia localiza-se nos quarteirões limitados pela Rua Fernando Palha e Rua do Vale formoso. Aqui observase uma densidade particular das atividades relacionadas com a classe CAE G45 comércio, manutenção e reparação de veículos automóveis e motociclos - havendo um largo número de stands afiliados a marcas e oficinas mecânicas que já desempenham funções há bastantes anos, passando muitas delas de geração em geração.

A segunda tipologia desenvolve-se no topo norte da Rua do Açúcar e em torno da Praça David Leandro da Silva. Aqui observa-se o surgimento de cerca de uma dezena de novas atividades, maioritariamente relacionadas com a restauração (classe CAE 156 restauração e similares) mas também com o lazer (classe CAE R93 - atividades desportivas, de diversão e recreativas). Distingue-se nesta área a criação do workhub $I x$, um novo espaço de trabalho partilhado no antigo edifício da antiga Sociedade 
PT | P01 | EP16| w2019

Comercial Abel Pereira da Fonseca, especializada na produção e exportação de vinhos que encerrou em 1993. No mesmo edifico abriu também o The Royal Rawness, que comercializa café e pastelaria.

A terceira tipologia, referente à zona intermédia da Rua do Grilo, é também visível aparecimento de algum comércio retalhista (classe CAE G47 - comércio a retalho exceto de veículos automóveis e motociclos, i.e., inclui comércio de produtos alimentares, de equipamentos eletrónicos, vestuário, livros, entre outros). Uma parte significativa destes novos estabelecimentos surge no piso térreo de um grupo de edifícios intervencionados.

A última tipologia remete para as imediações da Galeria Comercial da Rua de Xabregas. Aqui, apesar de existir uma percentagem de estabelecimentos que desapareceram, não deixa de ser percetível um claro agrupamento de restaurantes, mercearias e lojas de conveniência, algumas exploradas por imigrantes de proveniência de países asiáticos, originando a promoção de produtos de proveniência geográfica diversa.

Estruturalmente, a faixa oriental de Lisboa (um pouco à semelhança de outras zonas, como é exemplo o eixo Almirante Reis - Rua da Palma, ou Avenida da Republica e Avenida Duque de Ávila (Santos et al., 2017; Santos et al, 2019) mantém um comércio muito vinculado à atividade retalhista (classe CAE G47) e à restauração (classe CAE 156), representando $32 \%$ e $35 \%$ do total de estabelecimentos, respetivamente. Todas as atividades intimamente ligadas ao setor automóvel (classe CAE G45) também possuem uma boa representatividade. A proporção de empresas que desenvolvem atividade no setor dos serviços e lazer é ainda pequena, comparativamente às atividades com peso anteriormente descritas. Contudo, a sua presença tem vindo a ser mais notória, havendo um incremento de 9\% quando confrontados os resultados do recenseamento comercial de 2010 e do levantamento urbanístico de março de 2019. O aparecimento de estúdios de artistas, galerias de arte como a Underdogs, ou o centro cultural Fábrica Braço de Prata, com salas de concertos e exposições, entre outras, indica que esta zona oriental é também um local emergente para o lazer e a cultura na cidade de Lisboa. 


\section{estudoprévio}

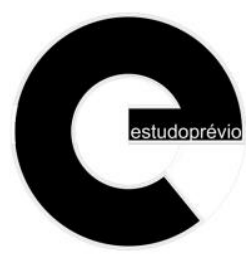

PT | P01 | EP16| w2019

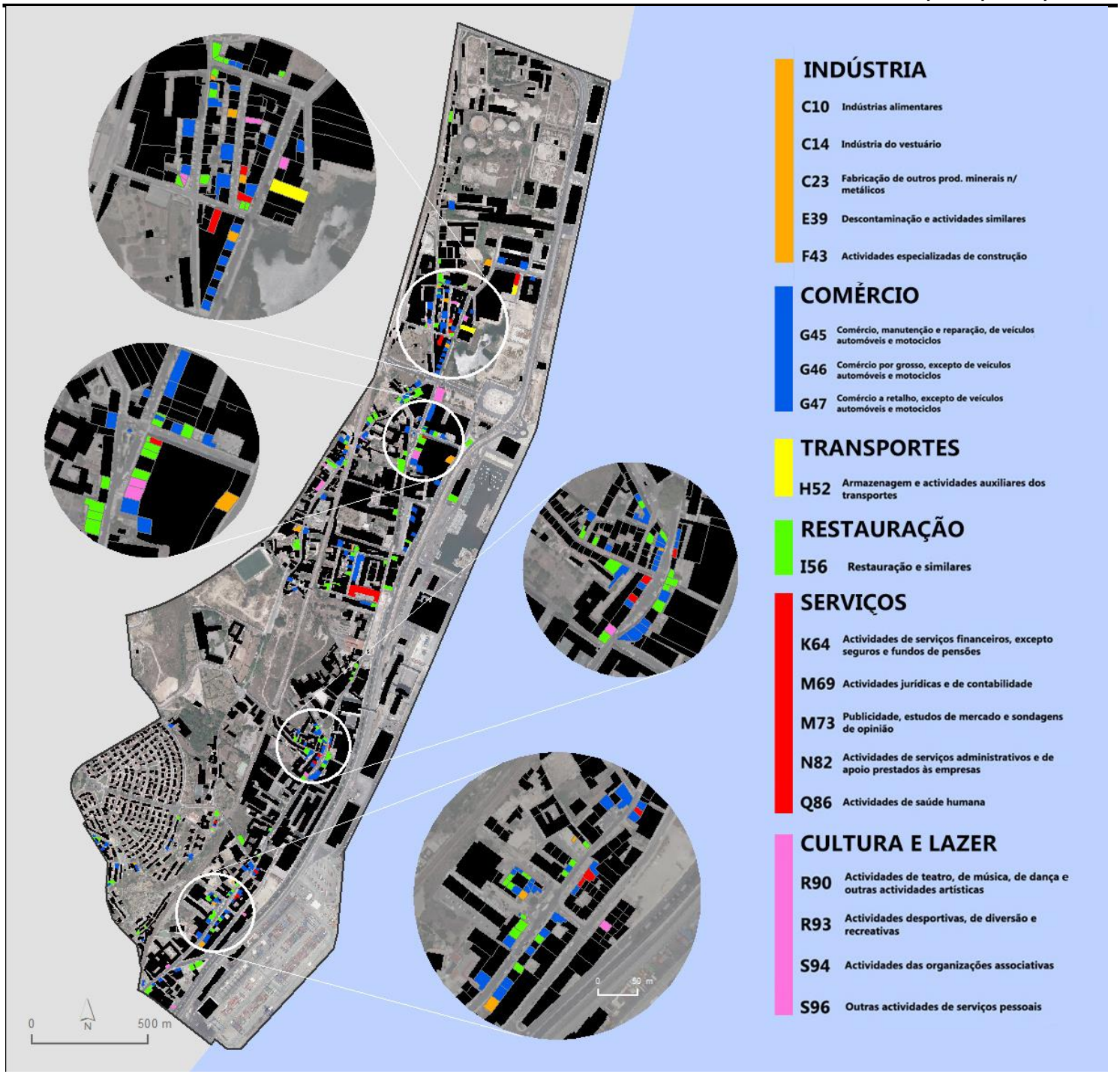

Figura 3 - Estabelecimentos comerciais por CAE Versão 3. Fonte: LU 2019; CML, 2010; INE 2011.

\section{O futuro}

$\mathrm{Na}$ área de estudo existem 3 espaços distintos, onde pode ocorrer uma transformação do território através da promoção de empreendimentos: os lotes referentes à antiga Sociedade Nacional de Sabões (SNS), que se fazem separar pela Estrada de Marvila, encontram-se hoje na forma de descampados. Esta fábrica fundada em 1919 através da fusão de outras indústrias do sabão, abriu insolvência em 1995, tendo acabado por encerrar em 1999. Estes terrenos, que se encontram ainda hoje na posse da família Rocha dos Santos (antiga detentora da SNS), foram propostos para uso habitacional no ano de 2011 através da empresa Obriverca SA, projeto esse que acabou por ser revogado pela Câmara Municipal de Lisboa. 
Outra das áreas com potencial para acolher transformação é o lote onde se estabelecia a antiga fábrica de gás da Matinha, desmobilizada totalmente em 2007. Aqui também se propõem o uso habitacional através da construção de 771 apartamentos divididos por edifícios que poderão chegar aos 21 andares. A Fimes Oriente, atual proprietária de $80 \%$ destes terrenos está próxima de avançar com o investimento uma vez recebido o aval da Câmara em 2018. No passado foi considerada a possibilidade de tornar parte deste espaço numa área verde urbana, proposta essa que teve parecer desfavorável da Administração do Porto de Lisboa e a Comissão de Coordenação e Desenvolvimento Regional de Lisboa e Vale do Tejo (CCDRLVT) por a operação não fazer referência ao processo de descontaminação dos solos (CMVM, 2015).

Um espaço também que poderá no futuro consolidar a ideia que faixa oriental de Lisboa está de facto em mudança é o quarteirão que se encaixa entre a Avenida Infante D. Henrique, a Rua de Cintura do Porto e a Rua Fernando Palha. O empreendimento iniciado em 1998 pela Obriverca SA, começa agora a dar os primeiros passos após ter sido comprado por ativos austríacos. Sob o nome Prata Living Concept, este projeto prevê a construção de 12 edifícios da autoria do arquiteto Renzo Piano ao longo de uma área bruta de $244000 \mathrm{~m}^{2}$, divididos em 12 lotes. Atualmente, observa-se uma profunda mudança do traçado urbano (onde ser inclui a implantação de um abrangente espaço verde junto ao rio) e a conclusão do primeiro edifício, que já começa a ser habitado.

\section{Conclusões}

De acordo com o levantamento urbanístico realizado, podemos concluir que a Faixa Oriental de Lisboa se encontra no caminho da renovação urbana e no afastamento progressivo da base industrial, reaproveitando o seu legado como fator de valorização cultural com o aparecimento de novos estabelecimentos dedicados àquelas atividades. A transformação induzida no espaço, através da ação sistémica de fatores tão variados como a alteração da estrutura setorial do emprego, o crescimento da procura turística em Lisboa ou a criação do estatuto de residente não-habitual, resulta não só numa oferta de habitação renovada e direcionada, em parte, para o alojamento local, mas também na construção de novos edifícios residenciais em terrenos industriais. A par desta dinâmica, destaca-se a existência de antigos espaços industriais que, dada a sua dimensão elevada, podem ter no futuro um papel importante tanto ao nível da oferta habitacional, mas também ao nível da criação de novas áreas de lazer e recreio, potenciando deste modo o ambiente e a qualidade de vida nesta zona da cidade.

\section{Agradecimentos}

Este trabalho teve apoio do CICS.NOVA - Centro Interdisciplinar de Ciências Sociais da Universidade NOVA de Lisboa, no âmbito do projecto UID/SOC/04647/2013, apoiado pela FCT/MCTES através de Fundos Nacionais. O 2ํaํ autor é financiado por fundos nacionais através da FCT - Fundação para a Ciência e a Tecnologia, I.P., no âmbito da Norma Transitória - DL 57/2016/CP1453/CT0004. 


\section{Bibliografia}

ALVES, T. - Economia da noite e regeneração urbana em Lisboa. XVI Congresso lbérico de Geografia. Lisboa, 5 - 7 de novembro 2018, p. 138-147. ISBN: 978-972-636-275-3

CMVM Comissão do Mercado de Valores Mobiliários - Fimes Oriente Fundo de Investimentos Imobiliário Fechado. Relatório de gestão 2015. web3.cmvm.pt (consultado em dezembro de 2019).

INE - Instituto Nacional de Estatística. Estatísticas de Preços da Habitação ao nível local. 4º trimestre de 2018 - www.ine.pt (consultado em dezembro de 2019).

GASPAR, Jorge - Da Lisboa Oriental, o Oceano, o Tejo e o Mar Da Palha: Três Entradas Para Explicar Lisboa: Scripta Vetera, 2000.

OCHOA, R. A. - Dinâmicas de crescimento em metrópoles portuárias. Tensões a oriente da cidade de Lisboa. On the w@terfront, n. 7, set. 2005, p. 30-41. ISSN 1139-7365.

SANTOS, T., RODRIGUES, A. M., RAMALHETE, F., TENEDÓRIO, J. A. - O parque habitacional devoluto em Lisboa: medição e uso prospetivo. X Congresso Geografia Portuguesa-Os Valores da Geografia. Universidade Nova de Lisboa, 9 a 12 de setembro 2015. p. 329-334. E-Book-ISBN: 978-989-99244-2-0.

SANTOS, T., PEREIRA, M., VELEZ, S., ÁLVARO, C. - Dinâmicas de Reabilitação em Edifícios Devolutos Públicos na Cidade de Lisboa (2009-2018). XVI Congresso Ibérico de Geografia. Lisboa 5 a 7 de novembro 2018, p. 206-214. ISBN: 978-972-636-275-3

SANTOS, T., RAMALHETE, F. SOARES, N. - Edificado Devoluto na Área da Avenida Almirante Reis: Potencial de Regeneração. XI Congresso da Geografia Portuguesa-As Dimensões e Responsabilidade Social da Geografia. Universidade do Porto, 9 a 11 de novembro 2017, p. 25-28. E-Book-ISBN: 978-989-54030-2-8

SANTOS, T., SOARES, N., VELEZ, S., ENCARNAÇÃO, S. - Impacto da Requalificação do Espaço Público no Comércio e Serviços: Avenidas da República e Duque de Ávila. XII Congresso da Geografia Portuguesa - Geografias de Transição para a Sustentabilidade, Guimarães, 13 a 15 novembro 2019.

SILVA, Marcelo Vieira da - Habitar e reabilitar Marvila. [S.I.]: Universidade de Lisboa, Faculdade de Arquitetura, 26 jun. 2017.

\section{Referências Web}

Lisboa Aberta (Câmara Municipal de Lisboa), http://lisboaaberta.cm-lisboa.pt/index.php/pt/. Consultado a 20/8/2019

Património Arquitetónico (Direção-Geral do Património Cultural), http://www.patrimoniocultural.gov.pt/pt/patrimonio/patrimonio-imovel/patrimonioarquitetonico/. Consultado a 7/9/2019

\section{Biografias:}

João Carlos Hermenegildo Oliveira ingressou na licenciatura em Geografia e Planeamento Regional da NOVA FCSH no ano de 2016. Durante a licenciatura colaborou com o Centro Interdisciplinar de Ciências Sociais, desenvolvendo ao longo do seu último semestre um estágio curricular em que explorou as novas dinâmicas territoriais da faixa oriental de Lisboa. Tendo terminado o primeiro ciclo de estudos, é atualmente aluno de mestrado em Sistemas de Informação Geográfica - Tecnologias e Aplicações da FCUL, dedicando-se ao aprofundamento de conhecimentos na temática das geotecnologias.

Teresa Santos é doutorada em Geografia e Planeamento Regional (especialidade de Deteção Remota e SIG), Engenheira Florestal, Mestre em Sistemas de Informação Geográfica. Investigadora do CICS.NOVA, da Faculdade de Ciências Sociais e Humanas da Universidade Nova de Lisboa. 


\section{estudoprévio}

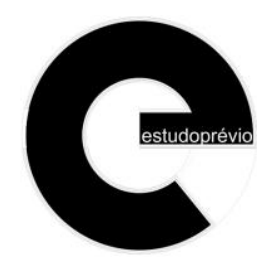

PT | P01 | EP16| w2019

Nuno Pires Soares é doutor em Geografia, Professor Auxiliar do Departamento de Geografia e Planeamento Regional da Faculdade de Ciências Sociais e Humanas da Universidade Nova de Lisboa. Investigador do CICS.NOVA, da Faculdade de Ciências Sociais e Humanas da Universidade Nova de Lisboa. 